\title{
Anti-CD20 B9E9 scFv-Streptavidin Fusion Protein
}

National Cancer Institute

\section{Source}

National Cancer Institute. Anti-CD20 B9E9 sCFv-Streptavidin Fusion Protein. NCI

Thesaurus. Code C121167.

An Escherichia coli periplasm-expressed tetrameric fusion protein composed of four sing le-chain variable regions (scFv) of the murine immunoglobulin (Ig) G2a anti-CD20 monoclonal antibody B9E9 fused to the streptavidin (SA) gene of Streptomyces avidinii (scFv-SA), with potential use in pretargeted radioimmunotherapy (PRIT). Upon intravenous administration of the anti-CD20 B9E9 scFv-SA fusion protein, this agent targets and binds to CD20-expressing tumor cells. Subsequently, a biotinylated Nacetylgalactosamine-containing clearing agent is administered, which binds to the streptavidin moiety of the unbound fusion protein and promotes its hepatic excretion. In turn, radiolabeled DOT A (1,4,7,10-tetraazacyclododecane-1,4,7,10-tetraacetic acid)biotin is administered and, due to its small size, quickly distributes. The biotin moiety efficiently binds to the SA moiety of the bound fusion protein, which localizes the biotinconjug ated radionuclide to the tumor site. CD20, a tumor-associated antigen (TAA), is overexpressed on B-cell malignancies. PRIT increases both tumor uptake and renal elimination of the radionuclide conjug ate as compared to conventional radioimmunotherapy (RIT), where the radioisotope is bound to the antibody before administration; this increases the dose of radionuclide delivered to the tumor while limiting radiation exposure for normal, healthy tissues. 